\title{
Performance Analysis of a Collective Solar Domestic Water-Heating System in the Temperate Zone of Yunnan Province, China
}

\author{
Zhiyong Zhou ${ }^{1, *}$, Liming Wang ${ }^{2}$, Chunxia $\mathrm{Li}^{1}$ and Alan Ebert ${ }^{3}$ \\ ${ }^{1}$ Faculty of Civil Engineering and Mechanics, Kunming University of Science and Technology, Kunming, Yunnan Province, 650500, China \\ ${ }^{2}$ China Academy of Building Research Beijing, 100013, China \\ ${ }^{3}$ Armstrong Fluid Technology, 23 Bertrand Avenue, M1L 2P3 Toronto, Canada
}

Received 1 May 2016; Accepted 21 June 2016

\begin{abstract}
Making a choice between a collective solar domestic water-heating system (CSDWHS) with a single water tank and one with double water tanks is a complicated problem for designers to solve, since it involves many influencing factors, such as cost, function, maintenance, etc. In this paper, a comparison of thermal performance of these two systems based on testing data was made in order to give some guidance to designers. Firstly, a CSDWHS with double water tanks installed in Yuxi, Yunnan Province was tested from 0:00 on 31 October 2015 to 8:00 on 1 November 2015 and from 0:00 on 3 November 2015 to 8:00 on 4 November 2015. Then, thermal performance indices (i.e., energy collected, daily useful energy gain, solar fraction, collector efficiency, system efficiency, system heat-loss factor, and average heat-loss factor) were analyzed to compare the thermal performance according to field-testing data. The results show that the system heatloss factor of the CSDWHS with a single water tank is lower than that with double water tanks, but the average heat-loss factor is higher, so it is difficult to conclude which system exhibits better thermal performance. Still, if real-estate developers do not emphasize cost and if there is enough roof space to place two water tanks, a CSDWHS with double water tanks is a feasible choice because it can store more heat to supply hot water for rainy or cloudy days. The results obtained in this study are useful for designers to optimize the design of a CSDWHS.
\end{abstract}

Keywords: collective solar hot-water system, water tank, collector efficiency, system efficiency, average heat-loss factor

\section{Introduction}

Since 1980, the solar domestic water-heating system (SDWHS) has been widely used in both rural and urban areas in China, with an annual average growth rate of $30 \%$ in China and a popularity rate of SDWHS use in urban areas almost reaching $25 \%$. Solar energy has thus played an important role in building energy efficiency in China via the development of the Chinese solar energy industry [1]. To encourage the application of SDWHSs, from 1 June 2012 to 30 May 2013, the Chinese government provided financial support for the purchase of high-efficiency SDWHSs, with the amount of the subsidy related to the type of SDWHS, its storage tank volume, and its energy efficiency.

According to Chinese National Standard GB 50176-93 (Thermal Design Code for Civil Engineering), 90\% of Yunnan Province is in a temperate zone, where it is cool in summer and warm in winter, and its annual average solar radiation reaches $5086 \mathrm{MJ} / \mathrm{m}^{2}$, so SDWHSs are widely used in this area. Owing to rapid urban growth, high-rise buildings make the collective solar domestic water heating system (CSDWHS) more popular in Yunnan. Making a choice between a CSDWHS with a single water tank and one with double water tanks is a complicated problem for designers to solve since it involves many influencing factors,

\footnotetext{
* E-mail address: zhiy_zhou@163.com ISSN: 1791-2377 @ 2016 Eastern Macedonia and Thrace Institute of Technology.All rights reserved.
}

such as cost, function, maintenance, etc. If only cost is considered, a CSDWHS with a single water tank should be a better choice. The situation changes if the weather is taken into account. In Yunnan Province, spring and summer constitute the rainy season and autumn and winter constitute the dry season. Thus, during spring and summer, there is high solar radiation on sunny days and low solar radiation on rainy or cloudy days. For a CSDWHS with double water tanks, solar energy gain on sunny days would be stored to supply hot water on rainy or cloudy days, which makes a CSDWHS with double water tanks a better choice. In this paper, a CSDWHS was tested twice under two sets of conditions, and the testing data were analyzed in order to give some guidance to designers.

\section{State of the art}

Some scholars have done much research to investigate and evaluate the thermal performance of SDWHSs both experimentally and theoretically. Amer et al. [2] developed a transient test method to characterize the dynamic behavior of flat-plate solar collectors, and the results are very close to those obtained from steady-state tests based on the ASHRAE 93-86 standard. Hayek [3] compared two kinds of solar collectors, one with an evacuated tube and one with a heat-pipe, and the results show that the heat-pipe-based collectors are better, with an almost $15-20 \%$ higher efficiency. A comparative study of two collectors with different tilt angles as measured from the horizon, with one 
inclined at $22^{\circ}(\mathrm{SWH}-22)$ and the other at $46^{\circ}(\mathrm{SWH}-46)$ by Tang [4], revealed that the collector tilt angle of a SDWHS had no significant influence on the heat removal from solar tubes to water storage tank. Therefore, both systems had almost the same daily solar thermal conversion efficiency, but a different daily solar gain and a different daily heat gain. Furthermore, the climatic conditions had a negligible effect on the daily thermal efficiency of the systems due to less heat loss from the collector to the ambient air. A field study of SDWHSs was executed by Moreaua et al. [5] under the auspices of a pilot project launched by the local government aimed at developing the SDWHS market in Québec, Canada, and the project demonstrated an average annual energy savings of $40 \%$. Theoretical work by Chow [6] indicated that a single-phase system had a better cost-payback period, and could be a suitable choice except for those locations with extreme cold weather. However, a two-phase design, important for supporting a zero-carbon building design, is an attractive and sustainable alternative since its thermal efficiency is higher under the same weather conditions. Wang and Zhou [7] analyzed the performance of a SDWHS for a high-rise apartment building in Yunnan Province, and the results affirmed that the thermal performance was qualified. Ayompe and Duffy [8] had collected data from a field trial to analyze the thermal performance of a SDWHS with heat-pipe collectors for one year in Dublin, Ireland. Hazami [9] predicted the performance of a SDWHS with evacuated tubes used for single-family households under a typical North African climate (Tunisia) by both experiment and theoretical research. Zhang [10] tested over 1000 solar collectors with water-in-glass evacuated tubes according to Chinese standards, and found that the heat loss of the storage tank and capacity of the solar collectors affected thermal performance. The influence of global solar radiation on the thermal performance of SDWHSs was studied by Wang et al. [11] based on simulation and experiment. Some research has been focused on the water-tank component of SDSWHSs; for example, Rodríguez-Hidalgo [12] presented a transient simulation program to determine the optimum size of a storage tank. Lia [13] carried out an experiment on the performance of the storage tanks in a SDWHS by studying discharging and charging efficiency. Some scholars are interested in new technology applied to SDWHSs; e.g., Benrejeb [14] presented an integrated collector storage solar water heater combined with a compound parabolic concentrator in order to improve the thermal performance of SDHWSs. Xue [15] researched the thermal performance of a domestic solar water heater with solar collector coupled phase-change energy storage. All of the above-mentioned studies concentrated on SDWHSs with a single water tank; studies of a CSDWHS with double water tanks, such as are popular in Yunnan Province, have seldom been undertaken.

\section{Methodology}

\subsection{Description of the CSDWHS tested in this study}

The CSDWHS tested, with its collectors installed on the roof of a six-story dormitory located in Yuxi (longitude 102.52 E, latitude $24.35^{\circ} \mathrm{N}$ ), Yunnan Province, supplies hot water for 128 persons. In the design phase, there were two schemes for the designers to choose from, shown in Figs. 1 and 2 ; the second scheme was ultimately chosen for the project.

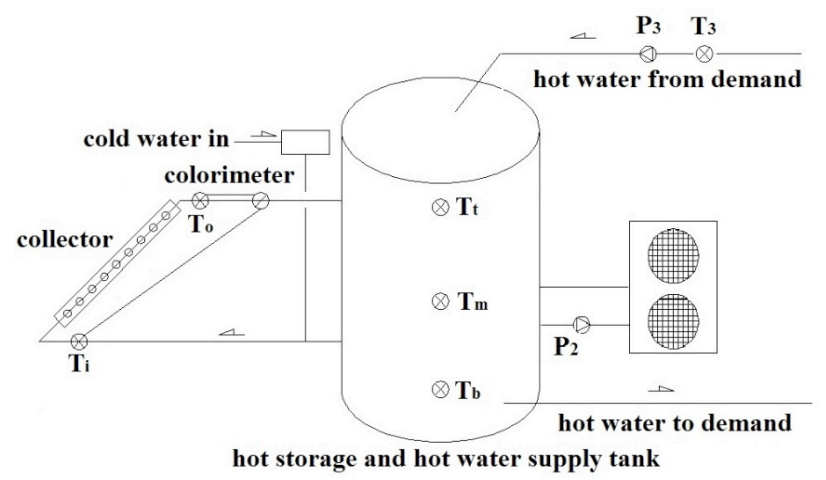

Fig. 1. CSDWHS with a single water tank.

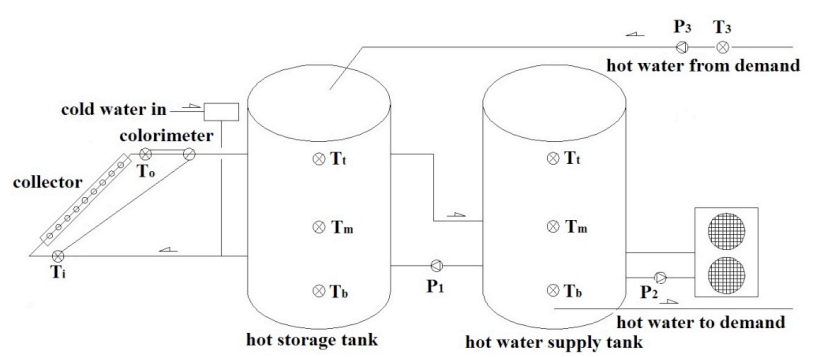

Fig. 2. CSDWHS with double water tanks.

The CSDWHS (shown in Fig. 3) has a total absorber surface area of $76.8 \mathrm{~m}^{2}$ and includes 12 vacuum tube collectors of the same size inclined at $45^{\circ}$, which are fixed on a prefabricated base and oriented southward; each collector consists of 50 vacuum tubes. The volume of the heat-storage tank and the hot-water supply tank is 5.5 and $3.5 \mathrm{~m}^{3}$, respectively. Both tanks are made of stainless steel and are wrapped in $50 \mathrm{~mm}$ polyurethane for heat insulation. There are three water circuits for the CSDWHS. For the solar circuit between the collectors and the heat-storage tank, water will circulate by natural convection, which is caused by the density gradient. For the heat-exchange circuit between the heat-storage tank and the hot-water supply tank, the pump $P_{1}$ between the two tanks will be turned on if the temperature difference between them is higher than the set value of $8^{\circ} \mathrm{C}$ and turned off if the temperature difference is lower than the set value of $2^{\circ} \mathrm{C}$. For the water loop between the two tanks and the hot-water users, the pump $P_{3}$ will be turned on when hot water is supplied or the temperature $T_{3}$ is lower than the set value of $45^{\circ} \mathrm{C}$. The hot-water supply tank is fitted with two air-source heat pumps of $10 \mathrm{PH}$ as an auxiliary heat source, and the pump $P_{1}$ will be turned on if the temperature of the hot-water supply tank is lower than the set value of $50^{\circ} \mathrm{C}$.

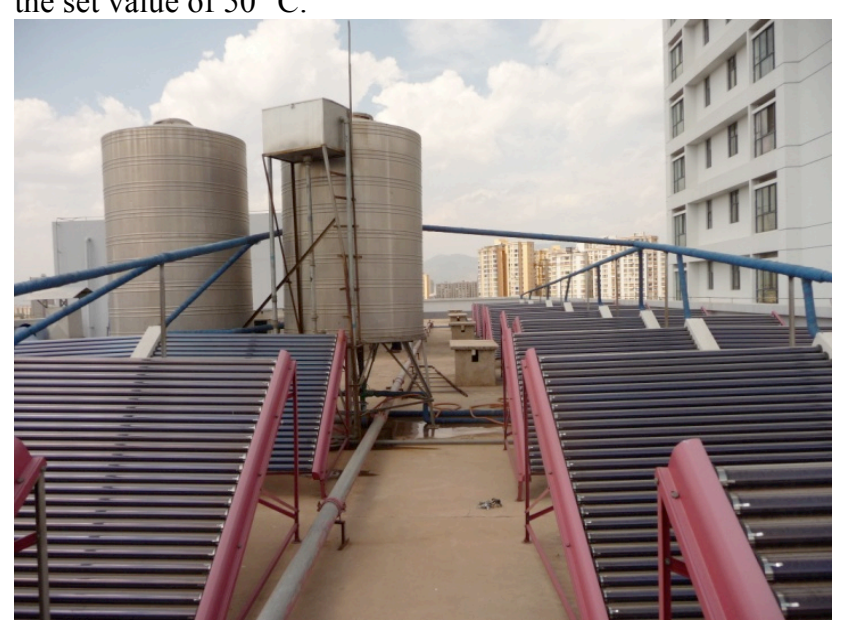

Fig. 3. Photo of the CSDWHS. 


\subsection{Test setup}

The first test for the CSDWHS with a single tank was carried out from $0: 00$ on 31 October 2015 to $8: 00$ on 1 November 2015 when pumps $P_{1}, P_{2}$, and $P_{3}$ were turned off. Figure 1 shows the experimental apparatus and the position of five Pt-100 platinum temperature sensors with a testing range from -50 to $+150{ }^{\circ} \mathrm{C}$ and an accuracy of $\pm 0.1{ }^{\circ} \mathrm{C}$, which were installed at the inlet and outlet to the collectors, and at the bottom, middle, and top of the heat-storage tank. The mass flow rate and the heat of the water in the collectors were measured by an HMW calorimeter with an accuracy of $\pm 2 \%$, located at the joint between the collectors and the hotwater storage tank. The test setup also included a DSFS-30 anemograph for measuring wind speed, with a testing range from 0 to $3 \mathrm{~m} / \mathrm{s}$ and an accuracy of $\pm 3 \%$; a testing box equipped with temperature sensors for measuring the ambient temperature, with a testing range from -40 to +70 ${ }^{\circ} \mathrm{C}$ and an accuracy of $\pm 0.2{ }^{\circ} \mathrm{C}$; and a CM11 pyranometer on the surface of the collectors for measuring the global solar radiation, with a testing range from 0 to $2000 \mathrm{~W} / \mathrm{m}^{2}$ and an accuracy of $\pm 2 \%$. The parameters measured and recorded every $3 \mathrm{~min}$ in the first test were as follows: the water temperature at the inlet to the collectors $\left(T_{i}\right)$, the water temperature at the outlet to the collectors $\left(T_{o}\right)$, the water temperature at the bottom of the heat-storage tank $\left(T_{b}\right)$, the water temperature at the middle of the heat-storage tank $\left(T_{m}\right)$, the water temperature at the top of the heat-storage tank $\left(T_{t}\right)$, the mass-flow rate $(m)$ of the solar circuit, the global solar radiation $\left(I_{t}\right)$, the ambient temperature $\left(T_{e n}\right)$, and the wind speed $(V)$.

The second test for the CSDWHS with double tanks (shown in Fig. 2) was carried out from 0:00 on 3 November 2015 to 8:00 on 4 November 2015, when pumps $P_{2}$ and $P_{3}$ were turned off and pump $P_{1}$ turned on. The parameters measured were the same as in the first test, but the $T_{o}, T_{b}$, and $T_{m}$ data were obtained for both tanks.

These two tests were divided into two phases. In the first phase, from 8 o'clock to 18 o'clock, $T_{i}, T_{o}, T_{b}, T_{m}, T_{t}, m, I_{t}$, $T_{e n}$, and $V$ were measured and recorded for calculating the energy collected, daily useful energy gain, solar fraction, collector efficiency, and system efficiency. $T_{b}, T_{m}, T_{t}, T_{e n}$, and $V$ were measured and recorded for calculating the average heat-loss factor in the second phase from 20 o'clock to 6 o'clock on the next day.

\subsection{Calculation of the thermal performance}

The thermal performance indices used in this study include energy collected, daily useful energy gain, solar fraction, collector efficiency, system efficiency, system heat-loss factor, and average heat-loss factor.

\subsubsection{Energy collected}

The energy collected by the solar collectors was calculated as follows [16]

$$
Q_{c}=\sum m C_{p}\left(T_{\mathrm{o}}-T_{i}\right) \times 10^{-3},
$$

where $Q_{c}$ is the the daily heat collected by the collectors during the first phase (MJ), $m$ is the water mass-flow rate in the collectors every $3 \mathrm{~min}(\mathrm{~kg}), T_{o}$ is the average water temperature at the outlet to the collectors every $3 \min \left({ }^{\circ} \mathrm{C}\right)$, $T_{i}$ is the average water temperature at the inlet to the collectors every $3 \mathrm{~min}\left({ }^{\circ} \mathrm{C}\right)$, and $C_{p}$ is the specific heat capacity of the water in the collectors, $4.187 \mathrm{~kJ} / \mathrm{kg}{ }^{\circ} \mathrm{C}$.

\subsubsection{Daily useful energy gain}

The daily useful energy gain of the CSDWHS was calculated as [17]

$Q_{u}=\rho C_{p} V_{s}\left(T_{e, a}-T_{b, a}\right) \times 10^{-3}$,

$q=\frac{Q_{u}}{A_{c}}$,

$q_{17}=\alpha \frac{q}{H}$

where $Q_{u}$ is the total daily useful energy gain of the tank during the first phase (MJ), $\rho$ is the density of water, 1000 $\mathrm{kg} / \mathrm{m}^{3}, V_{s}$ is the volume of the tank, $T_{b, a}$ is the average water temperature of the tank at the beginning of the first phase $\left({ }^{\circ} \mathrm{C}\right), T_{e, a}$ is the average water temperature of the tank at the end of the first phase $\left({ }^{\circ} \mathrm{C}\right), q$ is the daily useful energy gain $\left(\mathrm{MJ} / \mathrm{m}^{2}\right), A_{c}$ is the surface area of the collectors $\left(\mathrm{m}^{2}\right), q_{17}$ is the conversion value of the daily useful energy gain according to Chinese National Standard GB/T 20095-2006 (Assessment Code for Performance of Solar Water Heating System) $\left(\mathrm{MJ} / \mathrm{m}^{2}\right), \alpha$ is the conversion coefficient for the global solar radiation, $17 \mathrm{MJ} / \mathrm{m}^{2}$, and $H$ is the total daily global solar radiation absorbed on the collector surfaces during the first phase $\left(\mathrm{MJ} / \mathrm{m}^{2}\right)$.

$H$ can be calculated as

$$
H=\sum I_{t} t \times 10^{-6} \text {, }
$$

where $I_{t}$ is the total global solar radiation absorbed on the collector surfaces every $3 \mathrm{~min}\left(\mathrm{~W} / \mathrm{m}^{2}\right)$, and $t$ is the time interval, $180 \mathrm{~s}$.

\subsubsection{Solar fraction}

The solar fraction, which is the fraction of the total daily useful energy gain divided by the equivalent thermal energy of the daily hot-water demand, is the best indicator of the performance of the entire system, compared to the other parameters, which only show the performance of a single component [18]. It is calculated by [8]

$$
\mathrm{SF}=\frac{Q_{u}}{Q_{n}}=\frac{Q_{u}}{Q_{u}+Q_{\mathrm{aux}}}
$$

where $Q_{n}$ is the equivalent thermal energy of the total daily hot-water demand (MJ), and $Q_{a u x}$ is the daily auxiliary heatsource demand $(\mathrm{MJ})$.

$Q_{n}$ can be calculated as

$$
Q_{n}=q_{r} n c_{p}\left(T_{h}-T_{c}\right) \times 10^{-3},
$$

where $q_{r}$ is the daily hot-water demand per capita, 40 $\mathrm{kg} /$ person, $n$ is the number of daily hot-water users, 128 persons, $T_{h}$ is the hot-water temperature, $55^{\circ} \mathrm{C}$, and $T_{c}$ is the cold-water temperature, $15{ }^{\circ} \mathrm{C}$. 


\subsubsection{Collector efficiency}

The collector efficiency was calculated as [19], [20]

$\eta_{\mathrm{c}}=\frac{Q_{c}}{H \times A_{c}}$

\subsubsection{System efficiency}

The system efficiency was calculated as [19], [20]

$\eta_{\mathrm{s}}=\frac{q}{H}$

\subsubsection{System heat-loss factor}

The system heat-loss factor was calculated as

$\eta_{\mathrm{hl}}=\frac{Q_{c}-Q_{u}}{Q_{c}} \times 100 \%$

\subsubsection{Average heat-loss factor}

The average heat-loss factor was calculated as [17]

$$
U_{S L}=\frac{\rho C_{p}}{\Delta \tau} \ln \frac{t_{i}-t_{e n}}{t_{f}-t_{e n}} \times 10^{3},
$$

where $U_{S L}$ is the average heat-loss factor $\left(\mathrm{W} / \mathrm{m}^{3} \mathrm{~K}\right), T_{i}$ is the initial average water temperature of tank in the second phase $\left({ }^{\circ} \mathrm{C}\right), T_{f}$ is the final average water temperature of tank in the second phase $\left({ }^{\circ} \mathrm{C}\right), T_{e n}$ is the average ambient air temperature during the second phase $\left({ }^{\circ} \mathrm{C}\right)$, and $\tau$ is the test duration for the second phase, $36000 \mathrm{~s}$.

\section{Results: Analysis and Discussion}

\subsection{First test: Data analysis and discussion}

It was a cloudless day on 31 October 2015, typical weather for Autumn in Yunnan Province, and the weather data were used to analyze the performance of the CSDWHS. Figure 4 shows the global solar radiation during the first phase, with a maximum of $1276.39 \mathrm{~W} / \mathrm{m}^{2}$ at 13:48; the parameter $H$ calculated through Eq. (5) was equal to $23.47 \mathrm{MJ} / \mathrm{m}^{2}$.

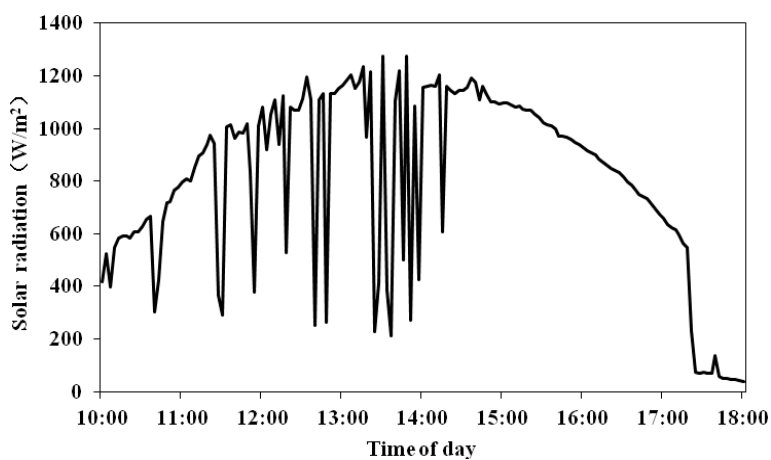

Fig. 4. Global solar radiation absorbed on the collector surfaces in the first phase.

Figure 5 shows the ambient air temperature and wind speed during the first phase, with a maximum ambient air temperature of $26.74{ }^{\circ} \mathrm{C}$ at $16: 54$ and a maximum wind speeds of $4.01 \mathrm{~m} / \mathrm{s}$ at 11:54; the average ambient air temperature and wind speed was $22.55^{\circ} \mathrm{C}$ and $1.78 \mathrm{~m} / \mathrm{s}$, respectively

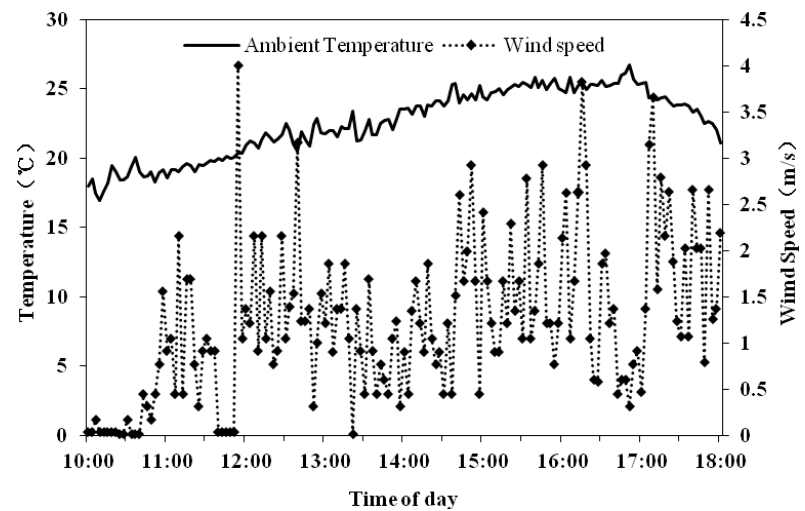

Fig. 5. Ambient air temperature and wind speed in the first phase.

\subsubsection{Energy collected}

Figure 6 shows the energy collected by the collectors in the first phase; the index $Q_{c}$, calculated through Eq. (1), was equal to $996.52 \mathrm{MJ}$. Comparing Figs. 4 and 6, a delay between the peak of the global solar radiation and the energy collected by the collectors was found, because the water in the collectors could not absorb the global solar radiation reaching the collector surfaces simultaneously due to thermal inertia.

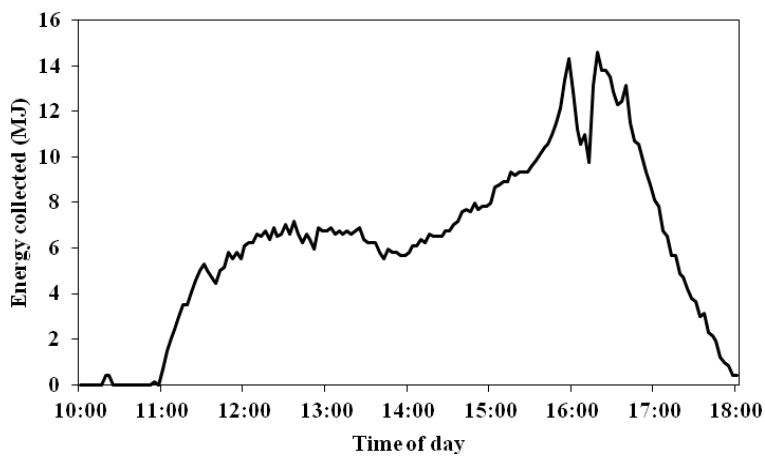

Fig. 6. Energy collected by the collectors in the first phase.

\subsubsection{Daily useful energy gain}

Figure 7 shows the water temperature curves for the top, middle, and bottom of the tank, which could not depict the thermal stratification distinctly because of the frequent mixing of the cold water and hot water; and the parameters $T_{b, a}$ and $T_{e, a}$ were $18.19^{\circ} \mathrm{C}$ and $61.12^{\circ} \mathrm{C}$, respectively. With $V_{s}=5.5 \mathrm{~m}^{3}$, the indices $Q_{u}, q$, and $q_{17}$, calculated through Eqs. (2)-(4), were 988.61 MJ, $12.87 \mathrm{MJ} / \mathrm{m}^{2}$, and $9.32 \mathrm{MJ} / \mathrm{m}^{2}$, respectively.

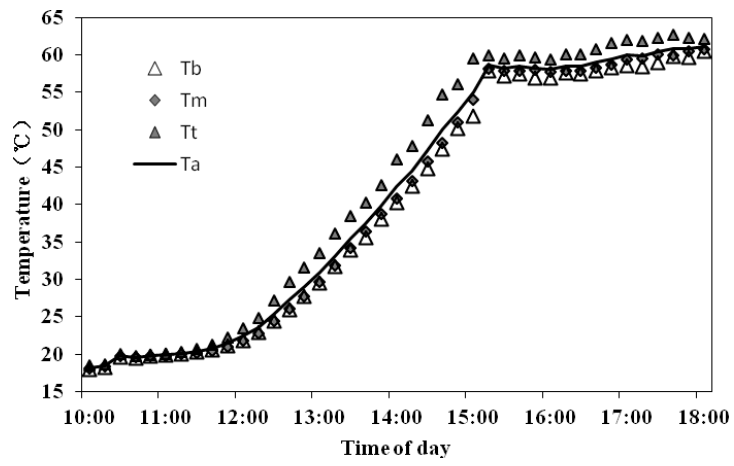

Fig. 7. Water temperature in the tank in the first phase. 


\subsubsection{Solar fraction}

The index $Q_{n}$, calculated through Eq. (7), was equal to 857.5 $\mathrm{MJ}$, and then the index $S F$ calculated through Eq. (6) was equal to $115.30 \%$, which means that there is no need for an auxiliary heat source.

\subsubsection{Collector and system efficiency}

Following the above calculations, the indices $\eta_{c}$ and $\eta_{s}$, calculated through Eqs. (8) and (9), were equal to $55.29 \%$ and $54.85 \%$, respectively.

\subsubsection{System heat-loss factor}

The index $\eta_{h l}$, calculated through Eq. (10), was equal to $0.79 \%$.

\subsubsection{Average heat-loss factor}

Figure 8 shows that the parameters $T_{i}$ and $T_{f}$ were $59.45^{\circ} \mathrm{C}$ and $56.70{ }^{\circ} \mathrm{C}$, respectively, with $T_{e n}=13.36^{\circ} \mathrm{C}$. Since all of the pumps were turned off and the system did not supply hot water to the users during the second phase, the stationary water made the thermal stratification more distinct. The index $U_{S L}$ calculated through Eq. (11) was equal to 7.16 $\mathrm{W} / \mathrm{m}^{3} \mathrm{~K}$.

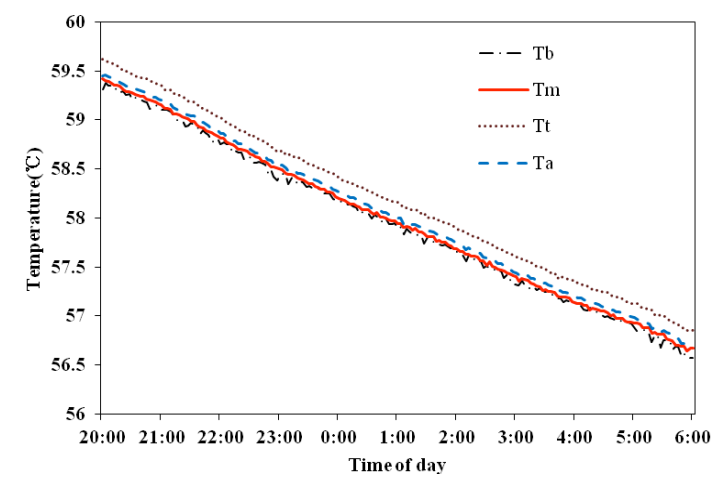

Fig. 8. Water temperature in the tank in the second phase.

\subsection{Second test: Data analysis and discussion}

For the second test carried out on 3 November 2015, which also was a cloudless day, the average ambient air temperature and wind speed in the first phase were $21.63{ }^{\circ} \mathrm{C}$ and $2.01 \mathrm{~m} / \mathrm{s}$, respectively, and the average ambient air temperature during the second phase was $12.84{ }^{\circ} \mathrm{C}$.

\subsubsection{Energy collected} $Q c=975.93 \mathrm{MJ}$ when $H=23.19 \mathrm{MJ} / \mathrm{m}^{2}$.

\subsubsection{Daily useful energy gain}

The parameters $T_{b, a}$ and $T_{e, a}$ of the heat storage tank were $17.35^{\circ} \mathrm{C}$ and $44.72{ }^{\circ} \mathrm{C}$, respectively, and those of the hotwater supply tank were $17.41^{\circ} \mathrm{C}$ and $40.39^{\circ} \mathrm{C}$, respectively. Thus, the indices $Q u, q$, and $q_{17}$ were 967.05 MJ, 12.59 $\mathrm{MJ} / \mathrm{m}^{2}$, and $9.23 \mathrm{MJ} / \mathrm{m}^{2}$ respectively.

\subsubsection{Solar fraction}

Following the above calculations, $S F=112.78 \%$, so there is also no need for an auxiliary heat source.

\subsubsection{Collector and system efficiency}

The indices $\eta c$ and $\eta s$ were $54.79 \%$ and $54.29 \%$, respectively, which suggests that the lower solar radiation, lower ambient temperature, and higher wind speed may be the factors influencing collector efficiency.

\subsubsection{System heat-loss factor}

The index $\eta_{h l}$, calculated through Eq. (10), was equal to $0.91 \%$.

\subsubsection{Average heat-loss factor}

The parameters $T_{i}$ and $T_{f}$ of the heat storage tank were 43.61 ${ }^{\circ} \mathrm{C}$ and $41.81{ }^{\circ} \mathrm{C}$, respectively, and those of the hot-water supply tank were $39.45^{\circ} \mathrm{C}$ and $37.93{ }^{\circ} \mathrm{C}$, respectively. The indices $U_{S L}$ for two tanks were 7.01 and $6.84 \mathrm{~W} / \mathrm{m}^{3} \mathrm{~K}$, respectively, which suggests that the tank volume and the temperature difference between the water temperature and ambient temperature might be the factors influencing $U_{S L}$.

\section{Conclusions}

In order to compare a CSDWHS with a single water tank and one with double tanks, a CSDWHS was tested twice, and the main conclusions based on the analysis of the testing data areas follows:

(1) The thermal performance indices of these two systems meet the requirement of Chinese National Standard GB/T 19141-2011 (Specification of Domestic Solar Water Heating Systems ), which stipulates that daily useful energy gain $(q)$ should not be lower than $7.7 \mathrm{MJ} / \mathrm{m}^{2}$ and average heat-loss factor $\left(U_{S L}\right)$ should not be larger than $16 \mathrm{~W} / \mathrm{m}^{3} \mathrm{~K}$.

(2) The collector efficiencies in the first and second tests were $55.29 \%$ and $54.79 \%$, respectively, which suggests that the lower solar radiation, lower ambient temperature, and higher wind speed might be the factors influencing the collector efficiency in the first phase.

(3) The system heat-loss factors in the first and second tests were $0.79 \%$ and $0.91 \%$, respectively, and the average loss factors were $7.16,7.01$, and $6.84 \mathrm{~W} / \mathrm{m}^{3} \mathrm{~K}$, which suggests that the heat loss of a CSHWS with double water tanks is higher than that with a single water tank in the first phase, but lower in the second phase, and that the initial water temperature and volume of the tank might be the factors influencing the heat loss in the second phase.

(4) The thermal performance of the two different CSHWSs tested was analyzed based on the testing data, so that effective measures could be taken to improve the energy efficiency of the entire system. The tests were conducted under experimental conditions in order to meet the relevant standard (GB/T 19141-2011), but more tests under actual conditions need to be done to verify the conclusions of this study.

\section{Acknowledgements}

The study was supported by the National Science Foundation of China under Grant No. 51268020 and the Applied Basic Research Program Foundation of Yunnan Province under Grant No. 2011FZ024 


\section{References}

1. R.Z.Wang, X.Q. Zhai., "Development of solar thermal technologies in China", Energy, 35 (11), 2010, pp. 4407-4416.

2. E.H. Amer, J.K. Nayak, G.K Sharma., "Transient method for testing flat-plate solar collectors", Energy Conversion and Management, 39 (7), 1998, pp. 549-558.

3. Michel Hayeka, Johnny Assafb, William Lteifb., "Experimental Investigation of the Performance of Evacuated-Tube Solar Collectors under Eastern Mediterranean Climatic Conditions", Biomedical Energy Procedia, 6 (1), 2011, pp. 618-626.

4. Runsheng Tang, Yuqin Yang., "Comparative studies on thermal performance of water-in-glass evacuated tube solar water heaters with different collector tilt-angles", Solar Energy, 85 (7), 2011, pp. 1381-1389.

5. Alain Moreaua, François Laurencellea., "Field study of solar domestic water heaters in Quebec", Energy Procedia, 30, 2012, pp. 1331-1338.

6. Tin-Tai Chow, Yu Bai., "Selection between single-phase and twophase evacuated-tube solar water heaters in different climate zones of China" Solar Energy, 98(Part C), 2013, pp. 265-274.

7. Zhihao Wang, Zhiyong Zhou., "Analysis of the thermal performance of a solar water heating system in a high-rise apartment in Yunnan", Energy Education Science and Technology Part A: Energy Science and Research, 31 (3), 2013, pp. 1729-1736.

8. L.M. Ayompe, A. Duffy., "Thermal performance analysis of a solar water heating system with heat pipe evacuated tube collector using data from a field trial" Solar Energy, 90 (4), 2013, pp. 17-28.

9. Majdi Hazami, Sami Kooli., "Long-term performances prediction of an evacuated tube solar water heating system used for singlefamily households under typical Nord-African climate (Tunisia)", Solar Energy, 94 (8), 2013, pp. 283-298.
10. Xinyu Zhang, Shijun You., "Experimental investigation of the higher coefficient of thermal performance for water-in-glass evacuated tube solar water heaters in China", Energy Conversion and Management, 78 (2), 2014, pp. 386-392.

11. WANG Mei-di, LI Ming, JI Xu ea al., "Experiment and simulation study on performance of flat-plate solar water heater". Renewable Energy Resources, 31 (5), 2013, pp. 22-25.

12. M.C.Rodríguez-Hidalgo et al., "Domestic hot water consumption vs. solar thermal energy storage: The optimum size of the storage tank", Applied Energy, 97 (9), 2012, pp. 897-906.

13. Shuhong Lia, Yongxin Zhanga, Kai Zhanga, ea al., "Study on performance of storage tanks in solar water heater system in charge and discharge progress", Energy Procedia, 48, 2014, pp. 384-393.

14. Raouf Benrejeb, Olfa Helal, Bechir Chaouachi., "Optical and thermal performances improvement of an ICS solar water heater system", Solar Energy, 112 (11), 2014, pp. 108-119.

15. Sheng Xue., "Experimental investigation of a domestic solar water heater with solar collector coupled phase-change energy storage", Renewable Energy, 86 (8), 2015, pp. 257-261.

16. Kalogirou, S.A., "Solar Energy Engineering: Processes and Systems. London", Elsevier, 2009

17. Tao He et al., "Specification of domestic solar water heating systems (GBT 19141-2011)", Beijing: China Standard Press, 2011.

18. Juliana Benoni Arruda Lima, Racine T.A. Prado., "Optimization of tank and flat-plate collector of solar water heating system for single family households to assure economic efficiency through the TRNSYS program", Renewable Energy, 31 (10), 2006, pp.15811595.

19. Duffie, J.A., Beckman, W.A., "Solar Engineering of Thermal Processes, third ed", New Jersey: Wiley, 2006.

20. Sukhatme, S.P., "Solar Energy: Principles of Thermal Collection and Storage", Tata, New Delhi: McGraw-Hill, 2012. 